\title{
A Review and Evolution of Chinese Policy on College Students' Mental Health Education
}

\author{
Hujun Peng ${ }^{a}$, Xianhua Yang*,b \\ College of Humanities \& Social Sciences of Shangluo University, Shangluo, Shaanxi, China \\ a2672533683@qq.com,*b emery10818@sina.com
}

Keywords: mental health education, policy, college students, evolution

\begin{abstract}
In the last thirty years, college mental health education in China has achieved a great progress, with amounts of latest researching works. This paper firstly makes a brief review on the national college students' mental health education policies from the beginning of 21 st century, then focuses on the teasing part of policy evolution on the working side. This arrangement benefits both college researchers and educators to get the latest information of policies and to instruct and conduct practical work.
\end{abstract}

\section{Introduction}

With the sustainable development impetus of the social transformation and education in late 30 years, college mental health education in China has gained a great progress. Moreover, more studies, works and practices are conducted. These achievements are inseparable with the great importance the country attaches to this work. Specifically speaking, it is to some extent the country's contribution of national policies and actual practice of them to college mental health education that makes college mental health education more normalized, scientific, large covered and developed in every aspect. Xie Ruhua[1] analyzes the features of college mental health education course on the national policy vision. Shen Zhe[2] mainly analyzing the secondary and middle school side found out that our mental health education has a sense of moral, dominant and tender. Experts who studies the American mental health education like Luo Mingchun concludes that the education in America is continuity, scientific, legality and maneuverability[3]. Other experts like Li Guoqiang also found that foreign school mental health education is more professional, specific and flexible[4]. All these findings has a positive reference for the construction of our school mental health education service system and policy implementation. Since 1980s, school mental education policy progress in our country can be generally divided into four stages of brewing period (in 80s), formation period (in 90s), improving and deepening implementation period (in the early $21^{\text {st }}$ Century) [5] and comprehensively implementation period (from 2011 till now). However, we can conclude that there still lack of thoughts and studies on national policies on college mental health education. Normally speaking, colleges and universities are the main units of the research on the mental health education policy in our country. Due to the fact that college students are the main group of school mental health education, the policy of mental health education is an important guarantee for the development of college students' psychological health education. Then here are some questions. What are the policies for our college students' mental health education in recent years? And how they developed and evolved? These three questions are the foundation for us to 
learn, implement and carry out the policies. Teasing apart the answers and summing up them to these questions are the works to be done in this article.

\section{Review on the General Situation in China}

There have been carried out 12 national policies on college mental health education by entering into the 21st Century (specifically from 2001 to 2014). They are Opinions of the Ministry of education on strengthening the mental health education of College Students in 2011 (hereinafter referred as Opinions 2011), An Outline of the Implementation of Mental Health Education for College Students (for Trial Implementation) in 2002 (hereinafter referred as Implementation Outline 2002), Notice of the General Office of the Ministry of Education of the People's Republic of China on Further Strengthening the Work of Student Management and Mental Health Education in Colleges and Universities in 2003, Opinions of the CPC Central Committee and the State Council on Further Strengthening and Improving the Ideological and Political Education of College Students in 2004 (hereinafter referred as Opinions 2004), Opinions of the Ministry of Education, the Ministry of Health and the Communist Youth League on Further Strengthening and Improving College Students' Psychological Health Education in 2005 (hereinafter referred as Opinions 2005), Notice of the General Office of the Ministry of Education of the People's Republic of China on the Establishment of an Advisory Committee for the Mental Health Education of Students in Regular Institutions of Higher Learning, Guidelines for the Development of National Mental Health Work System (2008-2015) in 2008, Notice of the General Office of the Ministry of Education of the People's Congress of the People's Republic of China on Adjusting the Members of the Steering Committee of Students' Mental Health Education in General Institutions of Higher Learning, Basic Standards for Mental Health Education of College Students (for Trial Implementation) (hereinafter referred as Basic Standards 2011) and The Basic Requirements of the Course of Psychological Health Education for College Students (hereinafter referred as Basic Requirements 2011) in 2011, People's Republic of China Mental Health Act in 2012 and Notice of the General Office of the Ministry of Education of the People's Congress of the People's Republic of China on Adjusting the Members of the Steering Committee of Students' Mental Health Education in General Institutions of Higher Learning in 2014. This study mainly focuses on four key policies, mainly because they have a direct role in the psychological health education of college students.

\section{Policy Evolution in China on College Students' Mental Health Education}

There are some key words referred in students' mental health education policy. This study made a general review and teased apart the evolution process from the working system aspect and got the latest progress and information so as to better guide the practical work and education practice. Table 1 shows Key words list form policies on mental health education.

Implementation Outline 2002 and Opinions 2005 covers teaching, activities, counseling and prevention aspects, while the working systems are not covered until Basic Standards 2011. Main contents of this four systems in Basic Standards 2011 would be explicitly reviewed below.

\subsection{Teaching System}

Basic Standards 2011 firstly raised teaching system construction in 2011 February. There are requirements in two aspects. First is to ensure the role of classroom teaching in college students' psychological health education. Relative lesson system should be established and improved. Set up a required course or an elective one and offer an appropriate credit to guarantee the students received psychological health course education. Second, teaching contents should be normalized. Teachers should improve their teaching methods and combine theory and practice together. Also 
there should be a specific syllabus or basic teaching requirements to improve the effectiveness of classroom teaching in many ways and promote the teaching quality through teaching research and reform. Basic Requirements 2011 was introduced in May in the same year. This regulation further refined the teaching requirements from the course natures and teaching objectives, the main teaching content, curriculum design and teaching materials, teaching modes and methods, teaching management and supporting conditions, implementation organization and teaching evaluation six aspects. This marks it as the beginning of psychological health education for programmatic documents. Basic Requirements 2011 explicitly points out that the course of psychological health education is a kind of public course which integrates knowledge, psychology and behavior. On the teaching objectives, it can be divided into three levels: mastering the knowledge of self adjustment and the skills of self exploration, psychological adjustment skills and development three skills and forming a healthy self perception. The teaching content is divided into 3 parts of psychological health knowledge, self understanding of self development and improving one's ability of psychological adjustment cover 12 themes of introduction, psychological counseling, self-awareness, personality development, planning and development of students ability, learning psychology, emotional management, interpersonal communication, psychology and love relationship, stress management and coping, life education and coping with psychology crisis. Two kinds of flexible methods in curriculum setting are raised, but they are both clearly pointed out that it is a required course and covers all students. Teaching materials should be the most qualified textbooks. Teaching mode should set knowledge, experience and training as a whole, pay attention to the combination of theory and practice and cultivate students' practical ability. We should give full play to teachers and students in the teaching of initiative and creativity to fully mobilize the enthusiasm of students to participate in the development of interactive classroom activities. On teaching methods, teachers should employ a combination of teaching theory and students' actual practice, teaching and students' training. Besides, there are various resources, abundant teaching methods and social resources available as a supplement of teaching. In teaching management, the curriculum should be included in the teaching plan and training program. The main course should be set up 2 credits with 32 - 36 hours, the extension courses can be distributed according to the needs of students in different semesters. As for the conditions supporting, on one side, a specialized group of professional ethics, professional, reasonable structure, full of vitality teachers should be established. On the other side, schools should actively create conditions for the teaching to provide the necessary equipment and materials and equip with appropriate teaching sites. This work should be jointly organized by the student work department, the educational administration department, the mental health education and consulting institutions and the relevant teaching and research institutions. The content of the course teaching evaluation includes the students' understanding and mastery of the knowledge, and the improvement of the students' psychological adjustment ability.

\subsection{Activity System}

Basic Standards 2011 raises requirements on object, medium and subject aspects. First, schools should carry out activities for all students, create more forms of activities, expands more ways and actively create an uplifting atmosphere. Second, they should take fully use of school mediums like radio broadcasts to actively carry out promotional activities. They also should attach importance to the construction of the network platform, set up a special website (web pages) and make fully development and utilization of online educational resources. Third, schools should allow students fully play their main roles to meet their self-development psychological needs, play the important role of a whole class and support students to set up psychological associations, organize activities and popularize science knowledge to fully mobilize students' self-awareness, self education, self growth initiative, initiative. 
Table 1 Key words list form policies on mental health education

\begin{tabular}{|c|c|c|c|c|c|}
\hline No. & key words & $\begin{array}{l}\text { Implementation } \\
\text { Outline } 2002\end{array}$ & $\begin{array}{c}\text { Opinions } \\
2005 \\
\end{array}$ & $\begin{array}{c}\text { Basic } \\
\text { Standards 2011 }\end{array}$ & $\begin{array}{c}\text { Basic } \\
\text { Requirements } 2011\end{array}$ \\
\hline 1 & importance & $\sqrt{ }$ & & & \\
\hline 2 & missions & $\sqrt{ }$ & $\sqrt{ }$ & & \\
\hline 3 & contents & $\sqrt{ }$ & & & \\
\hline 4 & principles & & $\sqrt{ }$ & & \\
\hline 5 & methods & $\sqrt{ }$ & & & \\
\hline 6 & team building & $\sqrt{ }$ & $\sqrt{ }$ & $\sqrt{ }$ & \\
\hline 7 & guiding ideology & $\sqrt{ }$ & $\sqrt{ }$ & & \\
\hline 8 & leadership & $\sqrt{ }$ & $\sqrt{ }$ & & \\
\hline 9 & system mechanism & & $\sqrt{ }$ & $\sqrt{ }$ & \\
\hline 10 & working condition & & & $\sqrt{ }$ & \\
\hline 11 & teaching system & & & $\sqrt{ }$ & $\sqrt{ }$ \\
\hline 12 & activity system & & & $\sqrt{ }$ & \\
\hline 13 & counseling system & & & $\sqrt{ }$ & \\
\hline 14 & $\begin{array}{c}\text { prevention and } \\
\text { intervention system }\end{array}$ & & & $\sqrt{ }$ & \\
\hline
\end{tabular}

Notes: " $\sqrt{ }$ " means the specific policy source of this key word.

\subsection{Counseling System}

Basic Standards 2011 lists requirements from organization, mechanism and methods three aspects. First, Psychological consultation room should be set up. Counseling room can be set up in the department and student hostels and its open time should be able to meet the needs of students. Second, schools should establish and improve the system of duty, appointment, key feedback and so on, follow the ethical norms, strengthen the management of the case records of psychological counseling, adhere to the principle of confidentiality, and regularly carry out research and supervision of the case. Thirdly, carry out psychological counseling services by various group counseling activities, study and formulate the corresponding plan and implementation plan to help students to solve the psychological problems. Mental health education and advisory mail, telephone number, and websites of counseling services should be published to all students, with an open online consulting and network consulting services.

\subsection{Protection and Prevention System}

Basic Standards 2011 lists specific requirements for protection and prevention system from three aspects of protection, intervention and aftermath work. First, schools should adhere to the principle of prevention, pay attention to the popularization of knowledge and give full play to the role of the work network. Through the survey of freshman's mental health status, psychological crisis regular investigation and other ways and means, we can find students' psychological crisis in time. Focus more on the serious psychological students, and in accordance with the psychological situation in a timely manner to ease and intervene them. Schools also should strengthen the recovery and rehabilitation of students with mental illness after attention tracking. Second, it is needed to formulate intervention work plan and clear the work flow and the responsibilities of relevant departments. It is necessary to establish a scientific and effective referral mechanism in departments, the school mental health education and counseling agencies, school hospitals, mental illness medical institutions and other departments. For students with more serious psychological problems, schools should guide the students to the medical institutions for mental illness. For students who have serious psychological crisis, they should promptly notify their legal guardian, assist to do the monitoring work, and timely referrals to the medical institutions according to the relevant provisions. Referral process shall be recorded and well documented. Thirdly, schools should play an 
effective role in a psychological crisis aftermath in accordance with relevant provisions. They should pay more attention to providing supportive psychological guidance to the parties and their related personnel, and minimize the negative impact of the crisis. Also they should learn the lessons in time, and improve the ability of teachers and students to understand the psychological crisis and the ability to deal with the psychological crisis.

\section{Conclusions}

Generally speaking, there are limited but specific policies established on mental health education in recent 10 years. These policies cover a wide range of content, the introduction of the policy and the implementation of the spirit of the meeting to meet the needs of the community and the actual needs and improve the level of mental health education of college students, improve the quality of mental health of students. From the evolution of the policy, it is showing a characteristics of naturally progressive. The content of policies repeat with innovative change, with a tendency towards detailed instructions and clear transformation from a high degree generalization. There are both qualitative and quantitative requirements in the policies, which shows a change to the combination of qualitative and quantitative. After nearly 10 years of efforts, the policy finally clear out the mental health education status, guiding ideology, general requirements, content, task, principle, approach, a full-time staff, system, mechanism, research, leadership, funding, teaching system, activity system, consultation system and prevention system. With this evolution process of these policies reviewed, sorted, considered and summarized, it can provide important guidance and reference for the development of mental health education in colleges of China. Practice in colleges and universities further shows that policy research is helpful to improve and improve the effectiveness of students' psychological health education, and promote the scientific level of work.

\section{Acknowledgements}

This study is funded by Shaanxi Provincial Academy of Social Sciences project"Research on cultivation of College Counselors' psychological education ability"(item number:2013Z042).

\section{References}

[1] Ruhua Xie. Chinese College Students' Mental Health Education Development Features and Future Directions on the Policy View[J]. Career Horizon,2011(12):100-101.

[2] Zhe Shen, Ce Zhou. Development Characteristics and Tendency of Chinese Primary and Secondary Students' Mental Health Education on the Plocy View[J]. Journal of Teaching and Management, 2013(7):38-40.

[3] Mingchun Luo, Dan Su. Foreign Health Promotion Policy Revelation to the Construction of Mental Health Service System in China[J]. Journal of Southwest University:Humanities and Social Sciences Edition, 2008(5):48-53.

[4] Guoqiang Li, Fenglian Li. Characteristics and Enlightenment of Foreign Policy on School Mental Health Education[J]. Journal of Hunan Institute of Humanities,Science and Technology, 2015(1):103-106.

[5] Guoqiang Li, Fanghong Gao. Evolution and Prospect of Chinese Schools Mental Health Education Policy. Journal of Hunan Institute of Humanities,Science and Technology, 2013(2):76-82. 